\title{
Maternal Serum Copeptin for Early Prediction of Preeclampsia
}

\author{
LOBNA A. ABOELMAGD, M.Sc.*; AHMED M. HAGRAS, M.D.*; MORAD A. MORAD, M.D.** and \\ HESHAM M. EL-TOKHY, M.D.* \\ The Departments of Obstetrics \& Gynecology* and Clinical Pathology **, Faculty of Medicine, Tanta University
}

\begin{abstract}
Background: Pre-eclampsia is a serious complication of pregnancy however there is no single predictor of preeclampsia among women at either low or increased risk of pre-eclampsia. The increased maternal levels of copeptin may be involved in the pathogenesis of pre-eclmapsia and may be useful in the assessment of the severity of the disease.
\end{abstract}

Aim of the Work: The aim of this work is to study the value of maternal serum copeptin level measured during the first trimester of pregnancy in the prediction of preeclampsia.

Patients and Methods: An observational prospective study includes 80 primigravidae with singleton pregnancy and gestation 11-13 weeks and Copeptin was measured using the BRAHMS Immunoluminometric Assay (Thermo Scientific). Copeptin, a surrogate marker of vasopressin, has been associated with a decline in renal function and may be a useful alternative biomarker for Preeclampsia (PE).

Results: The maternal Serum copeptin was significantly higher in cases who later developed preeclampsia and is more higher in severe cases $(13.64 \pm 3.02)$ than mild cases of preeclampsia. (7.27 \pm 1.40$)$ compared to the normal group (4.66 \pm 1.24$)$ $(p$-value $=<0.001)$. The specificity was $92 \%$ and sensitivity of the test was $88 \%$.

Conclusion: Serum copeptin is higher as early as 13 weeks gestation in women who later developed pre-eclampsia than in cases who remained normotensive till full term and delivery, and is more higher in severe cases than mild cases of preeclampsia.

Key Words: Copeptin - Prediction - Preeclampsia.

\section{Introduction}

PRE-ECLAMPSIA is a serious complication of pregnancy. It continues to be a major cause of maternal mortality and perinatal morbidity and mortality [1].

It affects $3-5 \%$ of all pregnancies and about $10-12 \%$ of all primigravida [2] .

Correspondence to: Dr. Lobna A. Aboelmagd, The Department of Obstetrics \& Gynecology, Faculty of Medicine, Tanta University
Pre-eclampsia is characterized clinically by complex of signs including maternal hypertension and proteinuria with or without pathological edema. Signs may range between mild, moderate and severe. Pre-eclampsia usually occurs after the $20^{\text {th }}$ week of gestation, but, may develop before this time in the presence of trophoblastic disease [2] .

Endothelial dysfunction which is one of the early stages of atherosclerosis plays an important role in the pathogenesis of pre-eclampsia [3].

Insulin resistance and low grade systemic inflammation might contribute to the pathogenesis of this endothelial dysfunction [3]

Also, placental ischemia secondary to an initial defective placentation, generalized endothelial cell damage and dysfunction creates the pathogenic mechanisms underlying pre-eclampsia [4]

Pre-eclampsia is diagnosed by increased blood pressure $(140 / 90 \mathrm{mmHg})$ that occurred in pregnant woman after 20 weeks of gestation accompanied by proteinurea $(\geq 0.3 \mathrm{~g} / 24 \mathrm{~h})$ as defined by The National High Blood Pressure Education Program Working Group on High Blood Pressure in Pregnancy [5].

Severe pre-eclampsia is diagnosed if blood pressure was $160 / 110 \mathrm{mmHg}$ or higher after 20 weeks of gestation accompanied by proteinurea $(\geq 0.5 \mathrm{~g} / 24 \mathrm{~h})$ and occurrence of specific symptoms or abnormal kidney or liver function [5] .

Stress mediated hypothalamic-pituitary adrenal axis activation regulated by copeptin-plays a role in the pathophysiology of insulin resistance and metabolic syndrome [6].

Copeptin the C-terminal part of the AVP precursor is of 39 amino acids glycopeptides, copeptin together with vasopressin co-synthesized and cosecreted from posterior pituitary, therefore, it 
mirrors the amount of vasopressin in the circulation, but, copeptin is more stable in plasma and serum. The increased maternal levels of copeptin may be involved in the pathogenesis of pre-eclmapsia and may be useful in the assessment of the severity of the disease [7].

\section{Aim of the work:}

The aim of this work is to study the value of maternal serum copeptin level measured during the first trimester of pregnancy in the prediction of preeclampsia.

Copeptin, a surrogate marker of vasopressin, has been associated with a decline in renal function and may be a useful alternative biomarker for Preeclampsia (PE).

\section{Patients and Methods}

This study involved 80 Primigravidae with singleton pregnancy and gestation 11-13 weeks and attending Department of Obstetrics and Gynecology, at Tanta University Hospital during the period between June 2016 and June 2017. All patients were subjected to thorough history taking with special emphasis on gestational age (in weeks), history of medical disease (as chronic hypertension, renal disease blood diseases, diabetes mellitus, thyroid disorders, liver diseases, cerebrovascular or any neurological abnormality) and clinical examination regarding blood pressure and body mass index. Obstetrical abdominal ultrasound was done by Fukuda Denshi Uf-850XTD for gestational age (BPD, AC, FL), and Viability. Routine investigations as fasting blood sugar, liver enzymes, complete blood count, urine analysis, serum urea, uric acid, creatinine and estimation of serum copeptin were done.

A total of $5 \mathrm{ml}$ venous blood sample were withdrawn in plain chemistry vacutainer tube for blood chemistry and serum copeptin assay.

- The sample was left to clot for 30 minutes.

- Clotted sample was centrifuged for 15 minutes at approximately $1000 \mathrm{xg}$.

- Separated sera were stored at $-80^{\circ} \mathrm{c}$ to be opened at the end of the study.

- Copeptin was measured using Enzyme Linked Immunosorbant Assay (ELISA) technique using EIAab® Wuhan EIAab Science Co., Ltd, China.

- Ultrasonography was used to determine gestational age, fetal life.

Follow-up of the patients was scheduled every 4 weeks until 28 weeks then every 2 weeks until 36 weeks then every one week until delivery.

\section{Statistical analysis:}

Statistical analysis of the data was done by IBM computer using SPSS (statistical program for social science) Version 20 as follows: Description of quantitative variables as range; mean and SD; description of qualitative variables as number and percentage. ANOVA test (Analysis of Variance) was used to compare quantitative variables between groups; Chi-square test was used to compare qualitative variables between groups. Receiver Operator Characteristic Curve (ROC) was used to find out sensitivity, specificity, + ve predictive value $(+\mathrm{PV})$, - ve predictive value $(-\mathrm{PV})$ and accuracy.

\section{Results}

The maternal S.copeptin was significantly higher in cases who later developed preeclampsia and is more higher in severe cases $(13.64 \pm 3.02)$ than mild cases of preeclampsia. $(7.27 \pm 1.40)$ compared to the normal group $(4.66 \pm 1.24)(p$-value $=<0.001)$.

The specificity was $92 \%$ and sensitivity of the test was $88 \%$.

Table (1): Distribution of the studied cases as regards the later diagnosis of preeclampsia.

\begin{tabular}{lll}
\hline Result & $\mathrm{N}$ & $\%$ \\
\hline Preeclampsia & 17 & 21.25 \\
Severe & 8 & 10 \\
Mild & 9 & 11.25 \\
No preeclampsia & 63 & 78.75 \\
\hline Total & 80 & 100 \\
\hline
\end{tabular}

Table (2): Maternal serum copeptin in both groups.

\begin{tabular}{lccc}
\hline $\begin{array}{l}\text { Serum } \\
\text { copeptin } \\
(\mathrm{ng} / \mathrm{ml})\end{array}$ & $\begin{array}{c}\text { Mild } \\
\text { preeclampsia } \\
(\mathrm{n}=9)\end{array}$ & $\begin{array}{c}\text { Severe } \\
\text { preeclampsia } \\
(\mathrm{n}=8)\end{array}$ & $\begin{array}{c}\text { No } \\
\text { preeclampsia } \\
(\mathrm{n}=63)\end{array}$ \\
\hline Range & $5.66-9.67$ & $10.47-20.40$ & $1.8-8.0$ \\
Mean \pm SD & $7.27 \pm 1.40$ & $13.64 \pm 3.02$ & $4.66 \pm 1.24$ \\
F-test & & 45.003 & \\
$p$-value & \multicolumn{4}{c}{$0.001 *$} \\
\hline Mild \& Severe & Mild \& No & $\begin{array}{c}\text { Severe \& } \\
\text { preeclampsia }\end{array}$ & No preeclampsia \\
\hline $0.001 *$ & $0.001 *$ & $0.001 *$ \\
\hline
\end{tabular}

Table (3): Sensitivity, specificity and accuracy for copeptin.

\begin{tabular}{lccccccc}
\hline & AUC $\begin{array}{c}\text { Cutoff } \\
\text { (ngml) }\end{array}$ & $\begin{array}{c}\text { Sensi- } \\
\text { tivity } \\
\%\end{array}$ & $\begin{array}{c}\text { Speci- } \\
\text { ficity } \\
\%\end{array}$ & $\begin{array}{c}\text { PPV } \\
\%\end{array}$ & $\begin{array}{c}\text { NPV } \\
\%\end{array}$ & $\begin{array}{c}\text { Accuracy } \\
\%\end{array}$ \\
\hline $\begin{array}{l}\text { Serum } \\
\text { copeptin } \\
\text { (ng/ml) }\end{array}$ & 0.964 & 65 & 88 & 88 & 65 & 88 & 88 \\
\hline
\end{tabular}

AUC: Area Under Curve. 
AUC for serum copeptin level was 0.964, the specificity was $92 \%$ and sensitivity of the test was $88 \%$, with accuracy $91 \%$.

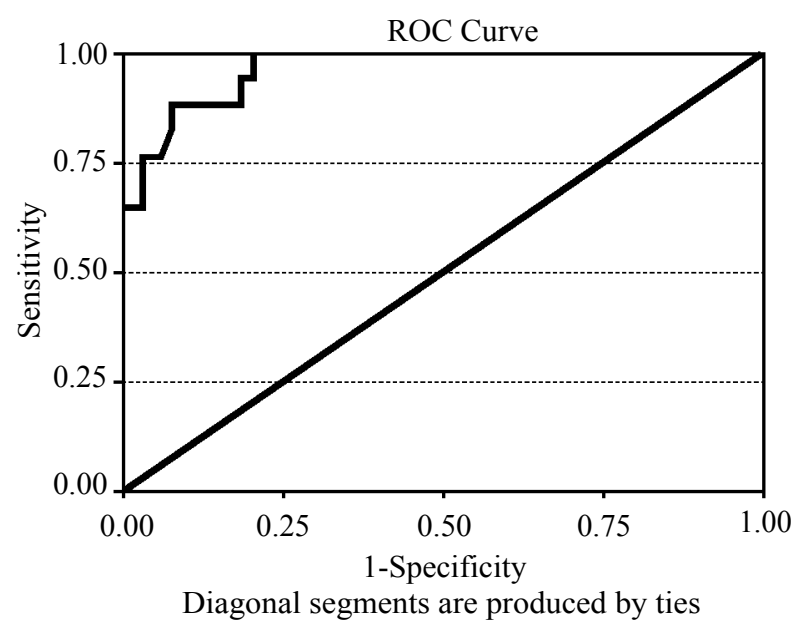

Fig. (1): ROC (receiver operating characteristic only curve) for copeptin.

\section{Discussion}

Pre-eclampsia is a serious complication of pregnancy. It continues to be a major cause of maternal, fetal and neonatal morbidity and mortality $[8]$.

It affects $3-5 \%$ of all pregnancies and about $10-12 \%$ of all primigravida [2] .

Pre-eclampsia is characterized clinically by complex of signs including maternal hypertension and proteinuria with or without pathological edema. Symptoms may range between mild, moderate and severe. Pre-eclampsia usually occurs after the $20^{\text {th }}$ week of gestation, but, may develop before this time in the presence of trophoblastic disease [9] .

Copeptin the C-terminal part of the AVP precursor is of 39 amino acids glycopeptides, copeptin together with vasopressin co-synthesized and cosecreted from posterior pituitary, copeptin is produced in 1:1 ratio to AVP. Therefore, it mirrors the amount of vasopressin in the circulation, but, copeptin is more stable in plasma and serum because it has longer biological half life [10] .

Copeptin is considered a promising diagnostic and prognostic marker in different diseases including pre-eclampsia [7].

The present study was conducted in Tanta University Hospital. The study was carried out on 80 pregnant women with singleton pregnancy.

In our study, the plasma copeptin levels were increased in women who later developed pre- eclampsia and markedly increased with the increased severity of the disease when compared to women with normal pregnancies of similar gestational ages.

These results indicated the importance of copeptin in the pathophysiology of pre eclampsia and that maternal copeptin levels might be a novel marker up regulated in pre-eclamptic patients.

These results agreed with those of Edwina Yeung et al., whose study included 143 normotensive pregnant women. Mean (standard deviation) of copeptin among controls and PE cases were 3.88 (2.5) and 5.21 (4.7) pmol/1, respectively. Samples were collected on average at 15 weeks of gestation. A 1pmol/1 increase in baseline copeptin levels was associated with $16 \%$ increased odds of PE $\left(p^{1} / 4\right.$ 0.002), with similar associations for preterm PE (OR: $1.20 ; 1.07-1.35)$ and term PE (OR: $1.13 ; 1.02-1.25)$ [8].

No significant associations were found between copeptin and gestational hypertension (OR: 1.08; 0.97-1.19) or preterm birthwithout PE (OR: 1.06; 0.96-1.17) [8].

They concluded that copeptin levels are elevated as early as 15 weeks in women who later are diagnosed with preeclampsia [8] .

Also, these results agree with those of Yeung et al., who measured serum copeptin level in first, second and third trimesters and found that, there was high statistically significant difference of maternal serum copeptin between control group $(3.8 \pm 2.3) \mathrm{ng} / \mathrm{ml}$, all pre-eclampsia $(5.1 \pm 4.5) \mathrm{ng} / \mathrm{ml}$, preterm pre-eclampsia $(5.4 \pm 4.7) \mathrm{ng} / \mathrm{ml}$, term preeclampsia $(4.9 \pm 4.3) \mathrm{ng} / \mathrm{ml}$ and GHTN $(4.1 \pm 2.9)$ $\mathrm{ng} / \mathrm{ml}(p$-value $<0.001)$. From this study, copeptin levels rose with increasing gestational age in all groups but remained significantly higher among those who were diagnosed with pre-eclampsia [9] .

Also, these results agree with those of Wellman et al., who examined the ability of several cardiovascular biomarkers to predict preeclampsia in pregnant women presenting in triage and found that all cardiovascular biomarkers tested, including copeptin, were increased in patients who later developed preeclampsia. Maternal plasma levels of copeptin were measured throughout pregnancy in 54 control pregnant, 50 preeclamptic pregnant, and 33 nonpregnant women. Copeptin was assessed and found to be significantly higher, in all 3 trimesters, in pregnant women who subsequently developed preeclampsia when compared with women who remained normotensive throughout preg- 
nancy. Receiver operating characteristic curves of the data also revealed that maternal plasma levels of copeptin in all 3 trimesters, even as early as 6 weeks, were predictive of the development of preeclampsia, even when controlling for clinical covariates [10].

While, these results disagreed with those of Birdir1 et al., [11], who investigated the potential value of maternal serum copeptin, midregional proatrial natriuretic peptide (MR-proANP) and Procalcitonin (PCT) levels at 11-13 weeks' gestation in the prediction of preeclampsia. This was a retrospective case-control study in women attending for their routine first trimester ultrasound scan in pregnancy.

In summary, they concluded that the maternal serum copeptin, MR-proANP and PCT levels were higher in EO-PE and LO-PE, but the increase was not significant. Thus, they were not proven to be effective markers to screen for PE in first trimester [11].

The disagreement was because Cahit Birdir1 et al., performed their study on small number of their patient collective. Doppler measurement of the uterine artery and blood pressure measurements were not used for analysis because of missing data. There were some patients already taking lowdose aspirin at the time of study participation or beginning of pregnancy [11].

\section{Conclusion:}

Serum copeptin is higher as early as 13 weeks gestation in women who later developed preeclampsia than in cases who remained normotensive till full term and delivery, and is more higher in severe cases than mild cases of preeclampsia.

\section{References}

1- CHANG C.H., TSAI P.Y., YU C.H. and KO H.C.: Chang FM. Prenatal detection of fetal growth restriction by fetal femur volume: Efficacy assessment using three-dimen- sional ultrasound. Ultrasound Med. Biol., 33 (3): 335-41, 2007.

2- ROBERTS J.M. and GAMMILL H.S.: Preeclampsia: Recent insights. Hypertension, 46 (6): 1243-9, 2005.

3- RODIE V.A., FREEMAN D.J., SATTAR N. and GREER I.A.: Pre-eclampsia and cardiovascular disease: Metabolic syndrome of pregnancy? Atherosclerosis, 175 (2): 189 202, 2004

5- National High Blood Pressure Education Program: Working group report on high blood pressure in pregnancy. Am. J. Obstet. Gynaecol., 183: 51, 2000.

6- SALEEM U., KHALEGHI M., MORGENTHALER N.G., BERGMANN A., STRUCK J., MOSLEY T.H.J. and KULLO I.J.: Plasma carboxy-terminal provasopressin (copeptin): A novel marker of insulin resistance and metabolic syndrome. J. Clin. Endocrinol. Metab., 94: 2558-64, 2009.

7- KATAN M., MORGENTHALER N., WIDMER I., PUDER J.J., KONIG C., MULLER B. and CHRIST-CRAIN M.: Copeptin, a stable peptide derived from the vasopressin precursor, correlates with the individual stress level. Neuro. Endocrinol. Lett., 29 (3): 341-6, 2008.

8- EDWINA YEUNG1, AIYI LIU1, JAMES MILLS1, CUILIN ZHANG1, TUIJA MÄNNISTÖ1, NANSI BOGHOSSIAN1, CANDACE ROBLEDO1 and PAULINE MENDOLA11: NICHD, Division of I Copeptin levels are elevated in women prior to diagnosis of clinical preeclampsia Intramural Population Health Research, Bethesda, MD, 49 (3): xxx-xxx, 2014.

9- YEUNG E.H., LIU A., MILLS J.L., ZHANG C., MANNISTO Y., LU Z., TSAI M.Y. and MENDOLA P.: Increased levels of copeptin before clinical diagnosis of preeclampsia. Hypertension, 64: xxx-xxx, 2014.

10- WELLMANN S., BENZING J., FLEISCHLIN S., MORGENTHALER N., FOUZAS S., BUHRER C.A., SZINNAI G., BURKHARDT T. and LAPAIRE O.: Cardiovascular biomarkers in preeclampsia at triage [published online ahead of print May, 17, 2014]. Fetal Diagn Ther. doi: 10.1159/000361016. http://www.karger. com /Article/FullText/361016. Accessed August 4, 2014.

11- CAHIT B., KATHARINA J., ANCA D.S., ANTJE E., SABINE KASIMIR-BAUER1, ALEXANDRA GELLHAUS 1 R.K. and ANGELA K.: Maternal serum copeptin, MR-proANP and procalcitonin levels at 11-13 weeks gestation in the prediction of preeclampsia Published online: 15 May Springer-Verlag Berlin Heidelberg, 2015. 


\section{مستوى الكوبيبتين بمصل الام للتنبؤ المبكر

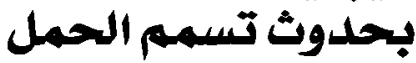

الهدف من البحث هو تقدير مستوى مادة الكويييتين فى مصل العيدة الحامل خلال الشهر الثالث الحمل ودراسة ما إذا كان يمكن إستخدامه إنها

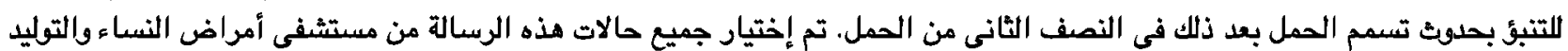

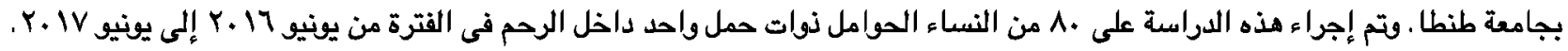

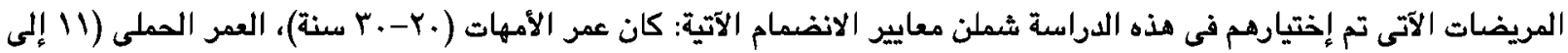

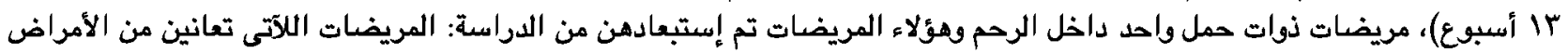

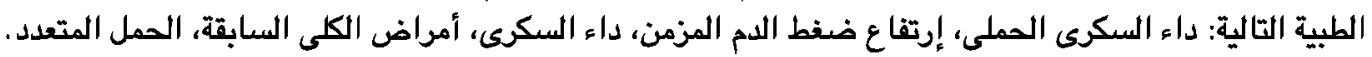

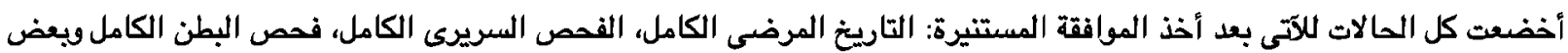

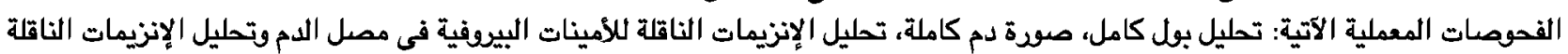

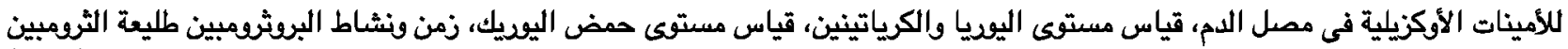

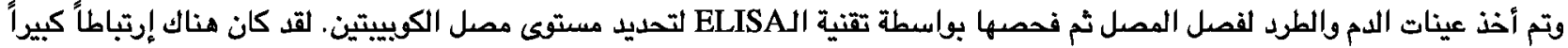

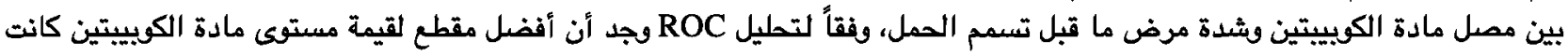

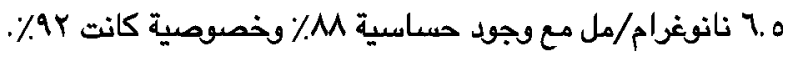

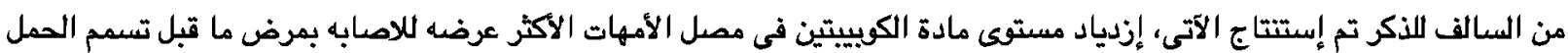

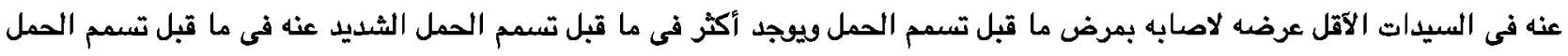

